\title{
Punk, ação e contradição em Portugal. Uma aproximação às culturas juvenis contemporâneas
}

Punk, action and contradiction in Portugal. An approach to contemporary youth cultures

Punk, action et contradiction au Portugal. Une approche aux cultures juvéniles contemporaines

\section{Paula Guerra}

\section{(2) OpenEdition}

\section{Journals}

Edição electrónica

URL: http://journals.openedition.org/rccs/5486

DOI: $10.4000 /$ rccs.5486

ISSN: 2182-7435

\section{Editora}

Centro de Estudos Sociais da Universidade de Coimbra

\section{Edição impressa}

Data de publição: 1 Dezembro 2013

Paginação: 111-134

ISSN: 0254-1106

\section{Refêrencia eletrónica}

Paula Guerra, «Punk, ação e contradição em Portugal. Uma aproximação às culturas juvenis contemporâneas », Revista Crítica de Ciências Sociais [Online], 102 | 2013, colocado online no dia 10 abril 2014, criado a 01 maio 2019. URL : http://journals.openedition.org/rccs/5486 ; DOI : 10.4000/ rccs. 5486

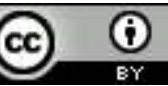




\section{PAULA GUERRA}

\section{Punk, ação e contradição em Portugal. Uma aproximação às culturas juvenis contemporâneas *}

O artigo aborda a atualidade do punk na sua abrangência e multiplicidade significante, tomando como referência o caso português. Com base em resultados de uma investigação alargada acerca do punk em Portugal, explora os significados culturais, sociais e simbólicos que se constituem em torno dessa forma de expressão estética que, afigurando-se em simultâneo como um ethos e um modo de estar na vida, revela um enorme potencial heurístico para a compreensão dos processos identitários e societais que atualmente se estabelecem em torno das cenas musicais. A abordagem do punk em Portugal permite retomar o debate em torno das culturas juvenis, no quadro da discussão ainda inacabada entre os cultural studies e as teorias pós-estruturalistas, ou seja, entre a teoria subcultural e a teoria pós-subcultural.

Palavras-chave: culturas juvenis; movimento punk; música popular; sociologia da cultura (Portugal); subculturas.

Passados quase 40 anos sobre a sua entrada no cenário musical, importa questionar a atualidade do punk enquanto subcultura juvenil, movimento

\footnotetext{
* Este trabalho foi realizado com o financiamento de fundos FEDER através do Programa Operacional Fatores de Competitividade (COMPETE) e por fundos nacionais através da Fundação para a Ciência e a Tecnologia, no âmbito do projeto "Keep it simple, make it fast! Prolegómenos e cenas punk, um caminho para a contemporaneidade portuguesa (1977-2012)" (PTDC/CS-SOC/118830/2010), liderado pelo Instituto de Sociologia da Faculdade de Letras da Universidade do Porto (IS.UP) e desenvolvido em parceria com o Griffith Centre for Cultural Research (GCCR) da Universidade de Griffith e a Universitat de Lleida (UdL). Conta ainda com as seguintes instituições participantes: Faculdade de Economia da Universidade do Porto (FEP), Faculdade de Psicologia e Ciências da Educação da Universidade do Porto (FPCEUP), Faculdade de Economia da Universidade de Coimbra (FEUC), Centro de Estudos Sociais da Universidade de Coimbra (CES) e Bibliotecas Municipais de Lisboa (BLX). Para além da autora deste texto, integram a equipa de investigação do projeto os/as seguintes investigadores/as: Ana Oliveira, Ana Raposa, Andy Bennett, Augusto Santos Silva, Carles Feixa, Hugo Ferro, João Queirós, Luís Fernandes, Manuel Loff, Paula Abreu, Paulo Lemos, Pedro Quintela, Rui Telmo Gomes, Tânia Moreira e Tiago Teles Santos. Para a recolha de dados, a equipa tem contado com o apoio de Ana Moreira, Filipa César, João Carlos Lima, João Matos, João Pereira e Pedro Barbosa.
} 
social e manifestação artística da contemporaneidade. A aceleração e a abrangência das mudanças artísticas, culturais, tecnológicas e económicas das últimas décadas são de tal forma intensas que, aparentemente, restaria pouco espaço para falar do punk no presente. No entanto, as manifestações punk na sociedade portuguesa atual revestem-se de um conjunto de traços que fazem delas, de forma que apenas aparentemente é paradoxal e inesperada, um objeto de análise sociológica de enorme relevo.

Com efeito, ao lado do escasso conhecimento até hoje disponível entre nós sobre este fenómeno, são múltiplas as razões que justificam que sobre ele se desenvolva um olhar atualizado e sistemático: pelo hibridismo e bricolage característicos desta (sub)cultura e pela sua notável inscrição no cerne dos processos estéticos, artísticos e culturais contemporâneos pós-modernos; pela manifestação musical e simbólica ainda omnipresente do punk e a sua imbricação com as paisagens culturais underground de uma série de cidades, como o Porto, Coimbra, Lisboa, Castelo Branco, Aveiro, Leiria, etc.; pelo ethos e a fundamentação ideológica-simbólica do punk e a sua associação à crítica e à contestação social; pela reivindicação e revivificação de um modus operandi Do-It-Yourself, tão importante na determinação dos novos movimentos sociais; pelo facto de o punk ter sido a porta de entrada para o desenvolvimento das (sub)culturas populares urbanas cosmopolitas na sociedade portuguesa; enfim, por existirem demasiadas ligações entre as afirmações identitárias da transição para a vida adulta e do ser jovem hoje e o que esse movimento, cena ou (sub)cultura tem reivindicado para si ao longo das décadas, numa perspetiva simultânea de globalização e localização, fragmento e coerência.

O presente artigo $^{1}$ procura justamente questionar a atualidade do punk nessa sua abrangência e multiplicidade significante, tomando como referência o caso português. Com base em resultados de uma investigação alargada de recorte diacrónico e sincrónico acerca do punk em Portugal, que privilegia uma abordagem qualitativa e a auscultação direta dos vários tipos de atores envolvidos na cena punk, o artigo explora os significados culturais, sociais e simbólicos que se constituem em torno dessa forma de expressão estética que, afigurando-se em simultâneo como um ethos e um modo de estar na vida, revela um enorme potencial heurístico para a compreensão dos processos identitários e societais que atualmente se estabelecem em torno das cenas musicais.

\footnotetext{
${ }^{1}$ Agradeço profundamente os comentários e sugestões dos meus colegas Augusto Santos Silva, Claudino Ferreira e Paula Abreu. Estes diálogos em muito enriqueceram o texto apresentado e as minhas reflexões acerca desta temática.
} 


\section{Um olhar com três focos, duas dimensões e uma abordagem}

"O punk teve que morrer para poder viver", diz Dylan Clark (2003: 223). Ora, é precisamente nesta linha que situamos o nosso primeiro foco de abordagem ao punk em Portugal e à discussão das formas de (sub)culturas juvenis que engendrou e continua a engendrar no nosso quotidiano. Assim, consideramos que o punk se demarca das subculturas clássicas que se opunham ao mainstream e à mercadorização, na exata medida em que tem sido um referente de intensificação mercantil, servindo de argamassa simbólica para a contínua, incessante e diferenciadora produção de objetos no capitalismo avançado. Nas palavras de Clark, "tendo ostensivamente neutralizado o punk, a indústria cultural provou ser capaz de comercializar qualquer subcultura juvenil." (2003: 227). Por isso, convidamos aqui a compreender a complexidade do punk: ${ }^{2}$ trata-se de uma (sub)cultura verdadeiramente contemporânea no sentido da contradição, da dialética constante entre underground e mainstream, da possibilidade de uma reinvenção incessante - exemplo claro do hibridismo e bricolage da cultura (O'Connor, 2002) e da hiperinflação dos códigos subculturais. Sabemos que a história da pop music se repete a si própria com regularidade, reinventando novas cenas underground como respostas à hegemonia mainstream (Azerrad, 2002). É neste entendimento que traçaremos uma abordagem preliminar da emergência, da vivência e da atualidade do punk em Portugal, considerando-o na atualidade (sub)cultural da simultaneidade dos consumos, artefactos, discursos, práticas, subgéneros musicais (Brake, 1980; Burke e Sunley, 1998; Cox, 2011) e na sua heuristicidade de conceito aberto e plural, a redescobrir em função do contexto histórico e social em que é vivido. Assim, neste artigo, usaremos o punk e a sua penetração na sociedade portuguesa num contexto de mudança societal acarretada pela Revolução de Abril, de permeabilidade do país às indústrias culturais, da inauguração de novas componentes de consumo estético e musical, de emergência das culturas urbanas e do consumo mais alargado do pop rock; contexto particular de ilustração e discussão do punk sob o olhar das teorias subculturais e pós-subculturais.

Sabemos a importância da localização das manifestações (sub)culturais num território, num contexto. E este é o nosso segundo foco. Desta feita,

\footnotetext{
${ }^{2}$ Numa das tentativas mais bem conseguidas de definição do punk, Laing adianta que "Em geral, o punk rock era uma negação das tendências dominantes na música popular. Continha atitudes, abordagens ou material que haviam sido excluídas da prática da música popular, que em meados dos anos 1970 foi mais do que nunca dominada por um pequeno grupo de conglomerados multinacionais (EMI, CBS, RCA, WEA-Kinney, Philips-Polydor) e o seu controlo sobre a produção e a distribuição de discos" (Laing, 1978: 123). Mas o próprio Laing considera que "internamente, no entanto, o punk rock era intensamente contraditório, um facto mascarado pela ansiedade com que os meios de comunicação e a indústria da música o apresentaram como a última moda musical” (ibidem).
} 
trata-se de uma primeira aproximação à reestruturação social e simbólica do punk nos últimos 40 anos na sociedade portuguesa, seguindo um intento de contextualizar este fenómeno global a uma escala nacional, onde os protagonismos, as trajetórias e as configurações são necessariamente específicos e muito diferentes dos ingleses ou americanos, ${ }^{3}$ na senda do que foi feito por Adams (2008) ou Savage (2001), que contemplam características intrinsecamente anglo-saxónicas no movimento punk. Partimos do pressuposto de que a criação da música popular não é um assunto individual a ser entendido através de um foco na música ou no músico, mas, em vez disso, um processo multifacetado que apenas pode ser entendido no contexto do ambiente social em que é criado e apropriado, transformado em banda sonora e corps fait de um posicionamento, de um modo de vida. Com estes pilares, iremos, neste artigo, e privilegiando os discursos dos indivíduos, apresentar uma descrição, uma avaliação e uma análise do contexto em que o punk emerge e se desenvolve em Portugal, e simultaneamente, um exercício de definição e uma apresentação das trajetórias de pertença ao movimento, compreendendo que os indivíduos constroem significados particulares e coletivos para a sua participação (Haenfler, 2004: 428-429).

Finalmente, colocamos um foco nas representações, nos sentidos do que é o punk à escala portuguesa, atendendo "às ideologias, crenças e práticas específicas que fazem parte de uma subcultura e que a diferencia da cultura dominante" (Barret e Burleson, s.d.: 4). Este foco resgata a plasticidade das autorrepresentações dos participantes na cena punk portuguesa sob diversos papéis (músicos, editores, music lovers, seguidores, jornalistas) e das mudanças e transformações de conteúdo em função das pertenças geográficas e geracionais. É comummente aceite no estudo das culturas populares a relevância da fidelidade proximal aos discursos dos seus elementos, assim como o reconhecimento da mutabilidade do punk e da sua não apropriação hegemónica. Esta defesa de uma "ordem do discurso" foi bem fundamentada por Matula (2007: 25), quando advogou que o "espaço de oposição punk" era criado fundamentalmente através da própria

\footnotetext{
${ }^{3}$ Em termos empíricos, partimos de um conjunto alargado de entrevistas a protagonistas das diferentes cenas punk portuguesas com vista ao mapeamento diacrónico e sincrónico dessas dinâmicas em Portugal, assim como à realização de histórias de vida a atores-chave do punk português. Os discursos utilizados neste texto derivam dessas entrevistas, especificamente de um conjunto de 140 entrevistas realizadas até ao presente a atores provenientes do Porto, de Lisboa, de Coimbra, de Braga, de Castelo Branco, de Almada, de Setúbal, de Matosinhos e de Viseu. Utilizamos, e dado o caráter exploratório deste texto, excertos ilustrativos. Simultaneamente, também mobilizamos dados provenientes de um conjunto de fontes documentais que incluem a imprensa, fanzines, discos, etc. que materializam todo um conjunto de discursos em torno do punk por parte dos seus protagonistas.
} 
produção musical e da construção ideológica de uma narrativa. Na mesma ordem de razões de apologia de uma análise dos discursos, o punk, como referem vários teóricos, foi uma cultura construída através de um processo de colagem, um processo que agregou elementos da cultura dita de elite e da cultura popular e que, como refere Adams (2008: 3-4), acabou por "indiscutivelmente colocar num local privilegiado as mesmas instituições que procurava destruir." Por conseguinte, o punk pode ser estudado através da análise das trajetórias narrativas dos músicos e fãs numa colagem de sentimentos, pertenças, vínculos, afetividades e razões.

Mais: se atentarmos no conceito de "fluxo narrativo contínuo", podemos ainda mencionar que apesar de "as memórias e experiências de um indivíduo sobre o punk serem fragmentárias, o indivíduo cria uma narrativa coerente [...] que permanece consistente ao longo do tempo." (Albiez, 2003: 361). É então inevitável a referência a duas dimensões de análise utilizadas neste artigo: os discursos e os objetos (bandas e registos fonográficos). São dimensões quase indissociáveis, em que os objetos são extensões do discurso. Thompson aponta a este respeito as similitudes dos punks com o "verdadeiro colecionador" de Walter Benjamin. O "verdadeiro colecionador de punk", argumenta Thompson (2004: 124-125), "desfruta de uma relação com os objetos que não enfatiza o seu valor funcional, utilitário - isto é, a sua utilidade - mas estuda-os e ama-os tal como à cena, ao palco do seu destino", sendo o destino "o período, a região, a perícia, o antigo dono... todo o passado de um objeto [que] adiciona a uma enciclopédia mágica”.

Neste contexto, realizamos uma aproximação metodológica de caráter intensivo, socorrendo-nos de observações etnográficas, mas também de entrevistas semidiretivas e histórias de vida a mais de uma centena e meia de participantes na cena punk portuguesa ao longo das diferentes décadas e dos diferentes contextos. Este recurso insistente aos discursos também nos levou à procura de objetos, tais como bandas e fonogramas, tidos como extensões e materializações discursivas de relevo. A análise preliminar dos dados permitiu-nos traçar tendências e significados representativos acerca do punk em Portugal, das suas lógicas de estruturação e funcionamento enquanto cultura de pertença e comunidade de interesse sociabilitário e musical que oferece imensas possibilidades de discussão teórica em torno dos cultural studies e dos estudos pós-subculturais.

\section{Emergência de uma cena punk portuguesa}

A Revolução de Abril de 1974 funcionou como um catalisador de vontades, de reivindicações e de manifestações e, nesse âmbito, foi favorável ao eclodir das primeiras manifestações punk em Portugal. Na cidade de Lisboa, 
existiam pequenos grupos de jovens relacionados com os lugares cimeiros da hierarquia social e artística, que mantinham contactos sistemáticos com as novidades internacionais. Foi junto desses grupos que surgiu a vontade de ser punk, pondo em causa a noção, comummente aceite, de que o movimento punk surgiu espontaneamente da raiva da classe operária contra o sistema. Uma ideia já defendida por Albiez (2004: 1), que advoga que o punk partiu de uma conceção lentamente construída e desenvolvida por um grupo heterogéneo de radicais, de estudantes de artes, de músicos tanto da classe operária como da classe média e de jornalistas insatisfeitos com o que o rock se tinha tornado. Sendo um movimento demasiado complexo para ser entendido através de explicações unilaterais correspondentes às classes sociais num sentido tradicional, é importante relativizar a sua associação exclusiva à classe operária, assim como a uma filiação subcultural restrita, pois estas abordagens têm-se revelado incapazes de dar conta da crescente complexidade do "dinamismo cultural de uma sociedade onde identidades individuais complexas estão sempre em transição e as afiliações coletivas são parciais, seletivas e temporárias" (Hodkinson, 2003: 285). Observamos isso no discurso dos entrevistados:

Todo esse movimento em Lisboa era um núcleo também muito restrito, de 100 pessoas. Rapidamente entrei e encontrei uma identificação. (Rui, 50 anos, Mestrado, Braga)

Quando a noção do movimento punk chegou a Portugal, nós já estávamos cheios de punks. Essa é que é a realidade. A revolução tinha sido há muito pouco tempo, vivia-se ainda aquela euforia toda. E havia muita gente que sempre tinha calado o bico que de repente começou a exprimir-se. Era como se o punk já existisse cá, mas sem estar referenciado, sem ter código de barras. (Bernardo, 51 anos, Licenciatura, Lisboa)

Nos anos 80, os punks eram da classe operária mas agora, com a internet, a adesão a este tipo de movimento está muito mais transversal, mas mesmo assim o underground ainda é restrito. Ainda me aparecem pessoas que gostam de punk pelas letras e pela atitude. Eu acho que por toda a Europa, as pessoas que estão ligadas aos movimentos de vanguarda são sempre mais das elites. (Marco, 41 anos, 9. ${ }^{\circ}$ ano de escolaridade, Porto)

Nestes primórdios do punk em Portugal, estava em causa não uma reivindicação propriamente de resistência classista, mas a afirmação de uma mudança de valores mais transversal, que envolvia uma abertura da juventude portuguesa a novas músicas, a novas estéticas, a novas formas 
de sociabilidade - no fundo, ao apanhar de um ritmo da modernidade. Coloca-se, aqui, a necessidade de rever o modelo subcultural desenvolvido pelos teóricos do Centre for Contemporary Cultural Studies Birmingham (CCCS), pois os dados empíricos têm vindo a demonstrar que a complexidade e fluidez das práticas culturais juvenis não mais podem ser analisadas sob o prisma das subculturas como unidades homogéneas de gostos e pertenças baseadas em classes sociais. Bennett (2001) demonstrou bem isso quando referiu que as pertenças neotribais correspondem a uma grande variedade de gostos em termos de géneros musicais, isto é, um mesmo indivíduo pode ter filiações musicais diversas. As neotribos são, assim, uma configuração grupal mais fluida, mais transitória e objeto de uma fugacidade por parte dos seus membros, por contraposição às pertenças subculturais. Da mesma forma, a conceção de que "tanto a 'subcultura' como a cultura parental contra a qual é definida são formações coerentes homogéneas que podem ser claramente demarcadas" é objeto de crítica: as culturas juvenis contemporâneas são caracterizadas por uma cada vez maior complexidade - especialmente num mundo cada vez mais interligado, onde ideias, pessoas, músicas circulam numa escala e velocidade sem precedentes - que se afasta da "dicotomia de 'mainstream monolítico' - 'subculturas resistentes'” (Muggleton e Weinzierl, 2003: 7).

Verificamos, sobretudo a partir de finais dos anos 70 do século passado, uma efervescência punk centrada na cidade de Lisboa, que resulta da crescente abertura da sociedade portuguesa ao mundo, embalada pela aceleração da globalização, pela constituição de um mercado juvenil, pela intensificação da urbanização, pela mobilização cosmopolita e o avanço tímido das indústrias culturais à escala portuguesa. De forma preliminar, em meados e finais dos anos 1970, formaram-se as primeiras bandas de punk rock em Portugal. Nessa altura, surgiram nomes como os Aqui d'El Rock (Lisboa), Crise (Sintra), Faíscas (Lisboa), Minas E Armadilhas (Lisboa), UHF (Almada), Xutos E Pontapés (Lisboa), Tilt (Porto) - bandas, na sua grande maioria, oriundas da Grande Lisboa. A Área Metropolitana de Lisboa, e em especial a cidade de Lisboa, exibiriam de resto um comportamento de maior dinamismo quanto ao número de bandas surgidas até aos dias de hoje. Apesar de se ter assistido, sobretudo a partir dos anos 1990, a uma proliferação de bandas pelo resto do país, nenhuma cidade consegue acompanhar o dinamismo desta cidade. No entanto, o simples facto de existirem bandas em locais menos centrais, e para lá do litoral e das duas áreas metropolitanas, é revelador da importância do ethos Do-It-Yourself (DIY) no punk nacional. Aí, nesses territórios mais empobrecidos, o ethos DIY talvez se afirme de uma forma ainda mais autêntica. Provavelmente, 
os jovens dessas bandas confrontaram-se com limitações que exigiram mais invenção e improviso. Terão tido possivelmente de se movimentar mais para encontrar instrumentos - pois que, muitas vezes, não existem sequer lojas de venda de instrumentos nos locais de residência - ou até mesmo de improvisar esses instrumentos, novas formas de tocar, novos estilos dentro do punk; terão tido de se deslocar mais para arranjar locais para concertos ou até que organizar os próprios concertos (necessitando para isso de arranjar o espaço, o equipamento necessário para fazer a apresentação, etc.); terão tido de gravar as suas músicas de uma forma mais arcaica ou procurar o contacto de alguém que o fizesse - opção que acaba muitas vezes por ser descartada dados os custos de gravação, que não podem ser suportados devido às escassas oportunidades de apresentação em público $\mathrm{e}$, em consequência, às escassas oportunidades de ganhar dinheiro.

De forma variável, o facto é que as bandas punk foram surgindo em vários locais do território nacional. Nos anos 1980, para além do Grande Porto (onde, durante a década de 1980, surgem nomes como Cães Vadios, Guru Paraplégico e os Iconoclastas ou os Os Cães, a Morte e o Desejo) e da Grande Lisboa (Kú de Judas, Grito Final, Condenação Pacífica, Peste E Sida, C.I.A.neto, Corrosão Caótica, entre outros), surgem igualmente noutros locais projetos também conhecidos do público: Aveiro (Cagalhões, Inkisição ou Mentes Podres); Coimbra (Extrema Unção, Objetos Perdidos, É Mas Foi-se); Leiria (Alien Squad); Montijo (Jardim do Enforcado); Portalegre (Avô Varejeira); Viseu (Bastardos do Cardeal). Com a chegada dos anos 1990, a proliferação das bandas continua a estender-se pelo território nacional, e ao punk rock juntar-se-ia um estilo musical que a partir de então viria a angariar bastantes seguidores - o hardcore. Durante esta década, surgem bandas, por exemplo nos Açores (Manifesto, Sangue ou Punk, Palha d'Aço), em Alcobaça (Us Forretas Ocultos), Aljustrel (D.P.E.), Castelo Branco (Crime Loucura, Mind Yard), Faro (Pointing Finger), Figueira da Foz (Deskarga Etílika), Penafiel (Fora de Serviço), Guarda (Caos Social, Konflito Social, F.D.P.), Ovar (Cabeça de Martelo, Um Trinco no Mamilo). Com o advento dos anos 2000, surgem bandas em Évora (I.A.C.), Fafe (Jesus Cristas), Madeira (Raiva!!!), Mirandela (Má Sorte), Moimenta da Beira (The Un-x-pected), Odemira (Abandalhados), Paredes (Veneno, Gregórios, Quebra-Cabeças), Sabugal (Minoria Activa, Los K.O.Jones), Viana do Castelo (U.D.M., Fools Die, Mr. Miyagi), etc. A partir desta década, e sobretudo a partir da década de 2010, as sonoridades parecem experimentar cada vez mais o lado mais agressivo do punk, optando-se por tocar um hardcore mais sombrio ou por outras sonoridades pouco usuais até então - crust, $d$-beat .

Este rápido percurso pelas bandas e suas espacializações aponta para uma significativa quantidade, diversidade e hibridismo. De forma recorrente, 
no discurso dos entrevistados encontramos uma comparação com a realidade anglo-saxónica de legitimidade inspiradora (e até mimética) hegemónica. Se, por um lado, a nível internacional, os atores entrevistados associam a bandas como os Ramones e os Sex Pistols o início do movimento, por outro o punk é visto como algo que sempre existiu, seja enquanto atitude, seja - numa leitura em que se associa sempre, em certa medida, às raízes do rock ' $n$ ' roll a nível mundial - enquanto música praticada nas garagens a partir de um exercício de mimetismo dos discos que chegavam. Se é no dualismo entre EUA e Reino Unido e no "sincretismo cultural" que está a origem do punk (Lentini, 2003: 153), o punk português é assim marcado pelo clima de abertura e transformação do pós-25 de Abril de 1974, e caracterizado por um mimetismo/uma reapropriação face às realidades norte-americana e inglesa. Errickson (1999) dá precisamente conta das especificidades sociohistóricas que estiveram na origem fundadora do movimento nos EUA e no Reino Unido, mostrando essa sua plasticidade e consequente adaptabilidade aos contextos de vivência, em sintonia com as teses acerca da consolidação das cenas musicais (Bennett e Peterson, 2004). Temos, a partir dos entrevistados, posicionamentos distintos de reapropriação vivencial do punk em Portugal, inspirados numa matriz anglo-saxónica. Aqui, estamos próximos de Lentini, quando assevera que o punk, em vez de ser visto apenas como originário deste ou daquele país ou, como alguns referem, uma forma de imperialismo, deve ser analisado como um movimento global agregando uma diversidade de estilos, focos líricos e políticos (Lentini, 2003: 170), em função dos contextos e das estruturas societais.

Não querendo esgotar aqui todo o conjunto de argumentos reveladores da génese e consolidação da cena punk portuguesa, outro dado importante da sua materialização decorre da existência de registos fonográficos. Até ao final dos anos 1980, são raras as gravações sob a chancela de editoras. O modus operandi da maior parte das bandas era a gravação caseira de registos ou a gravação de concertos. Aqui assumem especial destaque os concertos no Rock Rendez-Vous (RRV) (Crise Total, ao vivo no RRV, 1985; Kú de Judas, ao vivo no RRV, 1985). A demo tape $e^{4}$ Condenados sem Julgamento dos Condenação Pacífica (1988) era, toda ela, constituída por gravações do RRV. Os anos 1990 inauguram uma certa consolidação da cena punk nacional pela efetivação de gravações de registos associadas a editoras (sobretudo a Fast ' $n$ ' Loud). Acompanhando as desigualdades

\footnotetext{
${ }_{4}$ Trata-se de um registo fonográfico amador que funciona como versão de demonstração ou demo de material promocional de uma banda, demonstrativa de um trabalho maior. As demos são lançadas com o objetivo de apresentar o trabalho das bandas às editoras.
} 
e assimetrias de desenvolvimento do nosso país, não é, portanto, de estranhar que, novamente, seja a Grande Lisboa a zona do país onde um maior número de bandas tenha lançado registos fonográficos: por um lado, as bandas tinham mais possibilidades de lançarem um registo fonográfico através de uma editora, dada a maior proximidade relativamente a estas; por outro, tornava-se também mais fácil conseguir as "gravações caseiras" dos concertos, perante o maior número de espaços para realização de concertos com disponibilidade para fornecerem às bandas as gravações.

Uma das formas de divulgação mais comuns e baratas que havia era a disseminação, primeiro pelos amigos e daí de mão em mão, das gravações de concertos que tivessem alguma qualidade. [...] Dos dez lançamentos importantes do punk português, pelo menos duas entradas são gravações de concertos no Rock Rendez-Vous: Crise Total e Kú de Judas. Para mim, esta gravação dos Crise é mais importante que o CD saído 10 anos depois. Quase toda a gente a conhecia, de Norte a Sul do país. (Renato, 43 anos, Licenciatura, Lisboa)

Contudo, também é possível encontrar registos fonográficos noutros territórios do contexto português. Para esta proliferação, muito contribuíram as demos e a maior importância das compilações. As demos e as compilações, sejam de editoras, de espaços ou de publicações periódicas, auferem, na verdade, uma importância que ainda hoje é bastante notória no panorama fonográfico punk, revelando, por um lado, o caráter efémero destes projetos - que não chegam a durar tempo suficiente para atingir o patamar da gravação de álbuns - e por outro os fracos recursos económicos das bandas, que não possibilitam gravar mais do que simples maquetas dos concertos e dos ensaios. Com a massificação da internet e das redes sociais, a divulgação destas maquetas, outrora "mão em mão" nos concertos, tornou-se mais fácil, assumindo apenas a forma digital. Por último, as representações e os objetos aqui abordados revelam o punk enquanto (des)ordem cultural, faceta da cultura popular juvenil plena de metamorfoses e fragmentos, a exemplo do que acontece com outras tribos e cenas da cultura juvenil urbana.

\section{Significados e definições do punk}

A propósito da configuração do punk português, podemos constatar que entre a formação de bandas e a realização de concertos tudo parece assumir uma forma marcada pela atitude DIY, ${ }^{5}$ já que toda a estrutura é partilhada

\footnotetext{
5 Valerá a pena relembrar David Byrne: "O punk não era um estilo musical, ou pelo menos não devia ter sido...era mais uma espécie de atitude 'fá-lo tu mesmo - qualquer um consegue fazê-lo' ('Do-It-Yourself - anyone can do it'). Se só consegues tocar duas notas de guitarra, descobre uma maneira de fazer uma música a partir disso" (in Bennett, 2001: 60).
} 
e posta em funcionamento pelos próprios. Este é o primeiro significado e conteúdo do punk. O DIY promove a criação de música e as iniciativas locais e surge, num primeiro momento, como uma alternativa à música comercial e, num segundo momento, como uma forma de os atores sociais revelarem a sua total oposição às grandes produtoras de música, que se regem pelo lucro e que fizeram com que a diversidade musical, assim como as maneiras de produzir e de falar sobre música, fossem bem circunscritas (Mattson, 2001: 72-73).

O punk é atitude. Simplesmente, é atitude, é o Do-It-Yourself (DIY) - fazeres tu mesmo, sempre fora da corrente. O punk para mim é uma maneira de ver o mundo completamente sem ser como nós o estamos habituados a ver. É uma forma de nos revoltarmos, protestar, ter uma visão completamente diferente, ser contra as normas, sempre contra. (David, 29 anos, Frequência Universitária, Penafiel)

O que me fez acreditar e dizer "eu vou ser músico" foi quando tomei contacto com o punk rock e com o hardcore. Pensar que se pode controlar o processo, é tudo muito mais despreocupado, com muito menos intermediários e a própria atitude é "qualquer um pode fazer" [...]. O facto de descomplexar o acesso à música fez-me sentir bem comigo próprio ou confiante o suficiente para decidir vou experimentar. Foi só preciso uma vez, sentado em frente à bateria. (José, 29 anos, Frequência Universitária, Lisboa)

Para lá do atomismo de uma atividade dinamizada por jovens e do sentido de pertença que acompanha um período da vida, existe também uma expressão que marca claramente a vida dos indivíduos e os acompanha sempre, desde o momento do seu contacto. Ou seja, embora pareçam uma minoria, há um conjunto de indivíduos que manifesta uma adesão total ao movimento, mantendo opções estéticas mais claras e participando ainda de forma ativa ao nível da dinamização e da produção musical, o que vai de encontro ao apontado por Andy Bennett (2006). No nosso caso, podemos afirmar que, apesar das especificidades inerentes à trajetória de cada um, todos se sentem punk. Os que têm bandas, os que tiveram bandas, os que organizam concertos e eventos, os que nunca organizaram, todos têm em relação ao punk o mesmo sentimento de pertença, numa leitura que é comum: o punk é mais que a música. É, para além da música, uma atitude, uma ética, uma forma de estar que ultrapassa as fronteiras do género musical, por muito underground que permaneça. Vamos assim ao encontro dos resultados dos estudos recentes em torno da cena punk australiana desenvolvidos por Bennett e Taylor (2012), que mostram que, apesar de revelarem 
uma visão crítica da identidade punk enquanto jovens, os punks mais velhos continuam a afirmar que os ideais punk mudaram completamente as suas vidas para melhor, tendo-lhes incutido 'saberes de rua' (street-wise outlook) e um sentimento de realismo.

Por outro lado, num exercício de comparação do caso português e noutros contextos geográfico-culturais, encontramos, ao mesmo tempo, uma reiteração do caráter mimético, presente principalmente ao nível das influências musicais, uma avaliação que aponta para uma falta de infraestruturas e atividades de apoio ao movimento (como punk houses e squats) que permitam alargar as suas esferas de ação, uma capacidade de intervenção, organização e dinamismo e, finalmente, um reconhecimento de que o movimento punk evolui e se constitui numa estreita relação com as especificidades de cada contexto local e nacional ao nível das mentalidades. Havendo diferenças em termos de vitalidade, dimensão, estrutura e organização, mantém-se uma lógica fortemente ancorada em princípios fundamentais do punk, que se prendem com o inconformismo: o DIY feito babitus (Tucker, 2006) e feito ethos, refletindo uma transformação dos agentes de consumidores em produtores culturais (Dunn, 2008: 198). Reencontramos aqui os valores normativos da comunidade punk identificados por Kieran James (2009: 128): a ética e estética DIY; a atitude de oposição ao capitalismo e à alienação inerente a esse sistema de produção; a defesa de um "ponto de vista ao nível da rua" ou de um "espírito proletário emotivo".

Tem essa componente que é de luta contra o sistema... tipo rebelião, inconformismo, muito DIY, muitas fanzines, tudo muito pequeno, tudo muito feito por cada um, sem nada de grandes custos... uma coisa para tentar divulgar. Qualquer banda que se diga minimamente punk evita sempre músicas com conteúdo vazio, [...] uma coisa mais generalista ou que falem de amor... (Hugo, 42 anos, Frequência Universitária, Lisboa)

A contenda entre o mainstream e o underground é ainda uma questão em aberto em Portugal. Se encontramos indivíduos que veem com naturalidade o crescimento em termos de público e a consequente maior aceitação de algumas bandas, outros apresentam posições duais e críticas. Sem uma estrutura que albergue o movimento e permita uma forma de vida alternativa, emergem dois polos: manter-se no punk "verdadeiro" e underground e criar uma forma alternativa de subsistência; ou fazer do punk a forma de subsistência e ora reformular o modo de vida, ora ceder em certa medida às vicissitudes da indústria musical. Sabemos que o punk é um conceito aberto à interpretação, objeto de ampla disseminação em termos de autenticidade. 
Existe uma plêiade de disputas sobre o que pode ser chamado de autêntico e essas discussões intermináveis abrangem, para além das bandas/ dos artistas envolvidos, opiniões sobre o racismo, o sexismo, a homofobia, o militarismo, a violência, o preconceito de idade, a desigualdade económica, a arte, a moda e muitas outras questões sociais, culturais e políticas (O'Hara, 1999). Entre estes dois polos situa-se um posicionamento que se prende com uma leitura que parte do caráter rebelde e mais político do punk e prevê a hipótese de as bandas poderem crescer, mantendo os princípios, e fazerem chegar a sua mensagem a mais pessoas.

Vários autores advogam a "morte do punk" e, com esta, a morte das subculturas clássicas (Clark, 2003; Cogan, 2010; Sabin, 1999). Estes grupos foram importantes para a alteração da ordem social em várias partes do mundo, sendo que sua a força provinha da capacidade de chocar, de desobedecer a normas estabelecidas. No entanto, tudo isto mudou, pois, com o tempo, estas transgressões à norma tornaram-se, por assim dizer, normais, ou seja, algo expectável, tendo estas narrativas sido incorporadas pelo reportório capitalista, que reconfigurou a imagem de "rebelde" num potencial consumidor. Dylan Clark considera mesmo que o punk acabou capturado e colocado "no zoo subcultural, em exposição para todos verem" (2003: 223). Isto levou a que o punk alcançasse um ponto de não retorno, tendo travado uma batalha em toda a frente contra o establishment; chegou-se inclusivamente ao ponto de certas bandas valorizarem tudo o que era rejeitado pelo mainstream, desde violação até campos de morte. Alguns aderiram mesmo ao fascismo (ibidem: 225). Com Bloustien, percebemos que o discurso punk é marcado visceralmente por uma mistura de humanismo liberal e de materialismo dialético, que apresenta o indivíduo como radicalmente autónomo e resistente à uniformidade (2003: 51). Entre os nossos entrevistados é possível encontrar marcas desta visão.

O punk é um movimento, para mim, acima de tudo de um grito contra as desigualdades e por aí, tudo o que são as minorias, os mais desfavorecidos, os mais recalcados, para esses são os punks que fazem sentido. (Emanuel, 41 anos, 9. ano de escolaridade, Lisboa)

É um modo de vida, mas de certa forma são conceções ao longo do percurso de vida de um indivíduo. Há pessoas que mudaram radicalmente com aquilo que foram e há pessoas que começaram a ver de uma forma mais analítica os mercados, os jogos de poder que existem e uma pessoa que foi formatada toda a vida para aceitar o sistema como ele é e com as mudanças que tem a nível da sua vida pessoal, medidas políticas e sociais que interferem na sua vida pessoal e não se revolta?! Acho que quem tenha 
passado pelo punk pelo menos esteve em contacto com uma cultura alternativa, com ideias alternativas, com inconformismo e com uma realidade política. (Marcos, 37 anos, $12 .^{\circ}$ ano de escolaridade, Lisboa)

Os indivíduos veem o punk como algo que lhes permite fazer parte de algo em que partilham uma base comum, um espírito e uma atitude DIY, um sentimento de pertença a uma comunidade que, para fazer uso da expressão mítica de António Sérgio, se constrói na base do direito à diferença (Guerra, 2010, 2011). Moore defende que o punk responde à "condição de pós-modernidade" de duas formas aparentemente contraditórias. A primeira apropriou-se dos signos, símbolos e estilos pós-modernos com o intuito de fazer paródia, chocar e perturbar a sociedade. A segunda, ao invés, pretendia afastar-se da "superficialidade da cultura pós-moderna", envolvendo "uma busca de autenticidade e de independência face à indústria cultural", numa postura de total rejeição da "cultura dominante dos meios de comunicação, da imagem e do hipermercantilismo" e de completa defesa da ética DIY (Moore, 2004: 307). A primeira variação da subcultura punk, que o autor apelida de "cultura de desconstrução", "foi mais prevalecente durante a explosão inicial do punk nos anos 70 , enquanto a segunda (ou 'cultura de autenticidade') é mais característica das subculturas 'hardcore' ou 'straight-edge' que emergiram durante os anos 80, especialmente nos Estados Unidos" (ibidem).

Assim, encontramos marcas de uma identidade de grupo, já que, por um lado, as próprias relações pessoais dos indivíduos são marcadas pela sua trajetória no movimento punk e, por outro, a dinamização do movimento implica um forte relacionamento entre os intervenientes, dado o seu papel dúplice enquanto produtores e consumidores. Relativamente aos estilos, encontramos uma heterogeneidade, tanto a nível musical como estético e estilístico, que parece resultar da configuração plural que o próprio punk acarreta, evidente na sua pluralidade de subgéneros.

Tendo em conta o autoposicionamento dos indivíduos enquanto diferentes da norma, é importante remontar a Muggleton (2000: 145), quando este refere que está em causa a celebração de um sentido de individualidade partilhada - porque a valorização da diferença não implica, nem deve implicar, uma construção de identidades e atitudes individualistas. Esta individualidade partilhada implica um elevado grau de comprometimento que é, no entanto, influenciado pela trajetória individual e pelo tipo de relação mais ou menos ativa que os indivíduos mantêm com o movimento. Por outro lado, está presente um sentimento de pertença permanente. Ainda que a atividade e o contacto com as bandas, os discos e os concertos 
abrandem, os entrevistados afirmam ainda um "ser punk", uma pertença a um movimento alicerçada naquilo que identificamos como o seu substrato ideológico. Ao mesmo tempo, estes indivíduos - descrentes face à política, sobretudo como participação partidária - assumem claramente posturas de resistência política, que em alguns casos são conflituais com as trajetórias de vida e obrigam a uma gestão dual de posicionamentos ideológicos e vida profissional.

Ainda que o presente artigo não tenha o objetivo de descrever o funcionamento interno do movimento, acreditamos ser possível encontrar no seu seio ambiguidades e vicissitudes que podem enquadrar mecanismos de luta e de distinção, que virão à luz a partir de uma análise profunda que confronte as representações com as práticas dos indivíduos. Segundo Simon, os Sex Pistols iniciaram uma transgressão quando desenvolveram uma série de comportamentos chocantes em público, completamente inéditos no horário nobre da televisão. A sua atitude era de confronto com a indústria musical e "incitou uma crise e um pânico moral subsequente", que os transformou aos olhos dos média, dos políticos e dos moralistas no “inimigo público número um" (Simon, 1997: 155). Apesar deste declínio da música punk, Simon verifica que foi criada com sucesso uma verdadeira comunidade punk por oposição à sociedade dominante. Por este motivo, a ideologia de um niilismo autodestrutivo foi destruída a partir do interior da própria comunidade, por já não poder expressar os sentimentos por ela partilhados.

Esta abordagem ao punk que valoriza a componente cultural e política lato sensu e culturais, por contraste com a tradicional abordagem em torno da música, não pretende reduzir a importância que esta última tem para as vidas dos indivíduos e para a sua relação com o punk, mantendo-se assim sensível à chamada de atenção de Phillipov (2006). Com DeNora (2000: 13), acreditamos que a música pode ser lida enquanto recurso que permite compreender uma situação e que a música atua como modo de expressão e elemento configurador dos signos característicos da identidade (Megías e Rodriguez, 2001: 11). Assim, e embora reconhecendo a importância e o impacto que o punk teve no quadro da música popular, obrigando a reequacionar questões relacionadas com as audiências, a mercadorização e os sentidos musicais, é importante frisar também que existem muitos atores para os quais o punk é mais do que uma questão musical (Phillipov, 2006: 384, 392).

Foi uma forma de uma maneira apartidária ter alguma ação política. Lá voltamos ao mesmo de o punk não ser só música. O que não quer dizer que não haja bandas niilistas como a Banda do Garrafão que tem aquela vertente mais... próxima do 
rock \& roll. [...] Há espaço para todos os gostos, mas eu acho que faz falta, senão o punk passa a ser tão banal como o heavy metal, o funk, o soul... (Luís, 30 anos, Frequência Universitária, Lisboa)

O punk... o que costumava dizer quando era puto, era que o punk era liberdade. E eu acho que é uma mistura de várias sensações, é tu criares a nível musical, político, maneira de estar e ver as coisas. [...] Mas a parte musical... há dias que não me apetece ouvir punk, mas é acima de tudo criares mecanismos que te sentes bem e o punk é aquela... é uma palavra só, mas que te leva a chamar coisas, no aspeto visual, na atitude perante as coisas e isso é que é um punk. (César, 29 anos, Frequência Universitária, Lisboa)

O punk rock é uma música de gajos vadios, gajos que não paravam em casa, gajos que não tinham paciência para aturar nem a mãe nem o pai, nem estarem fechados. Quem se fechava em casa eram os gajos intelectuais e pseudointelectuais que fizeram aquelas bandas mais estranhas. Os vadios, os gandulos mesmo, os marginais andavam aí na rua. [...] Andas para aí, ou roubas ou pedes a uma miúda, engatas uma miúda ou cravas isto e aquilo ou fazes uma banda e bebes de borla nos concertos. (Miguel, 37 anos, $9^{\circ}$ ano de escolaridade, Lisboa)

O punk, subtraído ao domínio das aparências, deixa de ser um estilo para se tornar numa identidade de grupo que se orienta em torno de um individualismo radical (Bloustien, 2003; Muggleton, 2000). A pouca relevância apontada à estética por estes indivíduos remete-nos para a não preponderância desta no quadro das manifestações punk. Ao contrário da imagem presente nos conscientes coletivos relativa ao modo 'como é um punk', imagem que é ainda adotada por elementos do movimento, as opções estéticas dos nossos entrevistados são não só diferentes entre si, mas também diferentes dessa representação global que se faz do punk. Ou seja, a tónica da pertença ao punk não poderá estar presente naquilo que não assume um caráter regular e normalizado. Ao inverso, a regularidade que encontrámos prende-se exatamente com um enunciado substrato ideológico, que estrutura e enquadra as diferentes componentes do movimento. Neste contexto, este substrato ideológico, ao permitir a apropriação e redefinição de culturas de resistência, constitui a garantia da manutenção da coesão social (Dunn, 2008: 201).

Assim, e de novo segundo Dunn, a atratividade do punk como forma de expressão pessoal e política reside na oferta de recursos para uma agência e um empowerment via desalienação, um ethos DIY e uma disposição anti-status quo (2008: 206): uma disposição que constitui “uma infração 
deliberadamente rude das normas estéticas e sociais" (James, 1989: 35). As perspetivas apresentadas apontam para um papel social do punk de forma alargada e um papel mais individual, que incide numa transformação dos indivíduos que contactam de forma direta com ele. Por outro lado, há também uma perspetiva que, ao contrário, se foca menos na questão grupal e de contexto e mais naquilo que Laing (1978) apelida de "táticas de choque", remetendo para um percurso de transformação individual e para uma atitude de avaliação reflexiva desse mesmo papel.

\section{Representações e vivências}

Tipicamente, os jovens tornam-se membros de (sub)culturas juvenis, que podem ser vistas como comunidades de significado e de identidade e que dão a um indivíduo uma sensação de pertença, lhe providenciam um reconhecimento de si próprio, uma sensação de empowerment e lhe suavizam as inquietações (Langman, 2008: 663). Verificamos também que a sua ligação a este tipo de (sub)culturas tem como momento inicial o contacto com bandas, editoras e imprensa musical (Cartledge, 1999: 145) ou com outros indivíduos que, por situação de vizinhança ou contacto em contextos como a escola ou grupos alargados de amigos, surgiram nas suas vidas.

Um gajo começou-se a vestir assim de forma esquisita quando tinha... Foi quando saiu na Música \& Som, em 79 ou quê, apareceu um artigo do António Sérgio, a dizer como é que um gajo se devia vestir, pronto. [...] No outro dia na escola estava tudo vestido daquilo que um gajo pensava que era. Qual foi a solução, para já cortar o cabelo, depois pedias à tua mãe os fatos velhos do teu pai, tu estavas quase do tamanho do teu pai, e era assim, com um blazer que tinha sido do meu pai. (André, 34 anos, Licenciatura, Porto)

Eu não acho que os punks vivam de forma diferente... quando era puto dava muito mais ênfase à estética. Claro que a partir do momento em que a palavra punk seja tão deturpada que já não dê para usá-la, então deixo de a usar. Um gajo já sabe que música punk há de ter distorção, há de ser um bocado mais rápida, há de ser um bocado primitiva e tribal. O punk para mim é ter consciência das desigualdades sociais. É fazer face a uma sociedade sem oportunidades. [...]. E era assim nos anos 80 quando ainda Portugal era uma sociedade fechada, como é hoje quando Portugal está inerte com a crise económica e o resgate da Troica. (Ricardo, 49 anos, $12 .^{\circ}$ ano de escolaridade, Lisboa)

A subcultura clássica, segundo Clark, "morreu” quando se tornou objeto de verificação social e atribuição nostálgica, quando se tornou convertível 
em mercadoria (Clark, 2003: 224). Esta perspetiva enfrenta quanto a nós um problema: o punk não pode ser visto como uma subcultura clássica como os mods ou os rockers, por exemplo. Não obstante, a morte do punk, no seu sentido clássico, dá-se não só aquando do enquadramento de bandas punk no circuito mainstream, mas também quando a estética punk, quando o próprio punk se torna um produto passível de ser comercializado em cadeias de lojas que vendem em massa. O resultado disso parece ser o extravasar dos substratos do punk para outras subculturas - a transversalidade do DIY ao nível da música, atualmente muito presente na música independente e alternativa, o relativo sucesso de editoras independentes também ao nível destas manifestações musicais, etc. Nesta ordem de ideias, é possível ler-se o punk a partir de um enquadramento que faz o punk existir antes do punk, enquanto atitude que preexiste à nomeação e o faz sobreviver à própria morte, mantendo-se a atitude com outros adereços. Assim, descentralizado, anti-hierárquico, móvel e invisível, metastizou-se e garantiu a sua continuidade sublimando-se, estando presente mas sem nome.

Seguindo a sugestão de Sean Albiez (2004), sem negar a validade de identificar a subcultura punk como uma comunidade mais ou menos definida, é importante considerar as suas diversas dinâmicas. As liberdades do punk são absolutas e é colocado do lado do indivíduo a aceitação ou não das regras dos outros (Sinker, 1999: 129). No entanto, o espaço de total liberdade é ao mesmo tempo um espaço marcado por incongruências e conflitos. Assim, encontramos indivíduos que, como vimos, assumiram uma relação mais matricial com o movimento, ao lado de indivíduos que tiveram atitudes mais centradas na questão da produção e consumo de música. Isto aponta para que o "sucesso" das trajetórias dependa do grau e da variedade da ação dos indivíduos. A permanência no punk enquanto membro ativo e integrado, por oposição a uma permanência de cariz mais "ideológico" e distanciado, está relacionada com o grau de dependência face ao outro, no quadro das redes que constituem o movimento. Por outro lado, a questão geracional, na linha do que defende Bennett (2006), dita também alterações no sentido de uma vivência mais distanciada do movimento.

Não podemos deixar de referir que subjaz nas narrativas dos nossos entrevistados uma espécie de renascimento subcultural relativizado. Não obstante a mercantilização do punk, existe um sentimento de revolta e repúdio em relação àquilo em que o movimento se tornou atualmente, reafirmando a tese de Clark de que a morte das subculturas ajudou à criação de uma das mais formidáveis subculturas: o punk (Clark, 2003: 224). O punk continua a possibilitar a existência de uma comunicação contra-hegemónica, que faz frente à mercantilização, apropriação e domesticação. São vários os meios 
usados nessa resistência: desde as redes sociais informais e descentralizadas da internet e das tours que permitem o fluxo de discos, fanzines, bandas, ideias e estilos; passando pelas gravadoras e lojas independentes; até à ética DIY e às bandas que gravam e lançam músicas por conta própria. A vivência do punk ensina que a divisão entre cooptação e contra-hegemonia é muitas vezes um espaço obscuro repleto de contradições (Dunn, 2008: 202-204).

\section{Punk is not dead, long life to punk! Uma conclusão}

Discutimos aqui a pertinência da abordagem das culturas juvenis dentro da discussão ainda inacabada entre os cultural studies e as teorias pós-estruturalistas, ou, dito de outra forma, entre a teoria subcultural e a teoria pós-subcultural. O debate está longe do seu termo, mas consideramos que o punk pode dar um forte contributo para o esclarecimento das posições no seu seio, assim como para a resolução de antinomias teóricas que têm vindo a caracterizar a sociologia e a antropologia neste dealbar do século XXI, no tocante às culturas juvenis e à música. Consideramos o caso do punk português como ilustrativo para a explanação e a discussão em torno das teorias anteriores. Não existe, neste artigo, um imperativo de exaustividade de evidência empírica, mas sim um intuito exemplificativo capaz de dar luz a questões teóricas em torno das culturas juvenis com expressão notável na música como aconteceu e acontece com o punk - justamente apelidado por Clark como a "última subcultura" (2003).

Uma das questões que podemos retirar da realidade portuguesa, e que serve de mote primeiro à discussão da teoria subcultural, prende-se com a data da chegada e o contexto histórico de emergência do punk no nosso país. Com efeito, as manifestações punk ocorrem em Portugal, como já se referiu sucintamente, sob o efeito de abertura da sociedade portuguesa pós-25 de Abril e não como corolário da existência de uma clara reivindicação identitária dos filhos da classe operária, tal como aconteceu em Inglaterra. Um dado importante e de singularidade do punk português prende-se com o facto de ele próprio ter sido a face mais visível das ritualizações cosmopolitas e artísticas das culturas juvenis em Portugal na primeira metade dos anos 1980, pelo consumo de bens simbólicos e estéticos, mas também pela produção de uma atmosfera artística e urbana que cruzou a noite, a moda, o cinema, o vídeo, a música, as artes plásticas, etc. Nesta altura, e sobretudo em Lisboa, eram imensos os seus cruzamentos com a new wave e o pós-punk. Mais tarde, e por efeito da entrada de Portugal na Comunidade Europeia em 1986, da liberalização da televisão e eclosão da televisão por cabo e da generalização do uso da internet, atingimos um pleno das manifestações juvenis ligadas ao punk. Nesta medida é importante constatar 
que ao contrário da abordagem seminal de Hebdige (1979), não existia nos primeiros punks portugueses um espírito de resistência classista, nem uma homologia cultural clara.

A evolução do punk em Portugal operou-se indubitavelmente pelo aumento do número de bandas e de registos fonográficos, sempre numa lógica de diversidade e hibridismo estilístico e lírico com cruzamentos evidentes com o pós-punk e a new wave. Certo é que nos anos 1980 o número de bandas era escasso e confinava-se a Lisboa e ao Porto, ao passo que, como já demonstrado, os anos 1990 assistiram a uma disseminação das cenas punk por toda a faixa litoral, urbana e atlântica do nosso país (Guerra, 2014). Nesta diacronia e espacialização das bandas, as desigualdades estruturais mantêm-se, correspondendo às desigualdades e assimetrias da produção e reprodução cultural no nosso país. Caso importante, e que aproxima a realidade portuguesa das teorias subculturais, é a estrutural e persistente oposição do punk português ao mainstream e à comodificação (Marcus, 1989). Neste ponto, existe uma aproximação à resistência subcultural dos anos 1970, não obstante podermos arriscar que essa resistência se deve em muito à inexistência de estruturas e canais de produção capazes de sustentar a cena punk portuguesa. A singularidade da cena punk portuguesa é ainda hoje dinamizada pela vivacidade e defesa do underground. Assim, são raras e objeto de intensas críticas as bandas punk que têm uma posição estabelecida na cena musical portuguesa; o punk português nunca conheceu processos de comercialização de massas, e permanece, passadas quase quatro décadas, numa reivindicação objetiva e subjetiva de "luta contra o sistema".

Por seu turno, a cena punk portuguesa parece também ir de encontro aos avanços da teoria pós-subcultural, designadamente por se tratar de um caso importante de hibridismo cultural vacilante entre o mimetismo e a recriação: nesse percurso mais irresoluto entre ambos os polos, não cedendo ao mimetismo, nem à recriação, o país apresenta hoje uma cena importante de punk marcada por diversos subgéneros, que coexistem em diferentes espaços geográficos, marcada por muita contingência e transitoriedade. $\mathrm{Na}$ atualidade, continuam a surgir bandas apoiadas em cenas locais nas zonas urbanas do país, com uma existência mais ou menos efémera, com a realização de ensaios, com a organização de concertos e de festivais muito pouco formalizados e estruturados. Por isso, não deixa de ser relevante considerar que o universo punk português movimenta um conjunto de atores que desempenham em simultâneo vários papéis dentro da cena, neste sentido policêntrica: são músicos, são promotores, são editores, são fãs, fazem fanzines, são managers, etc. 
Quando abordamos os sentidos e significados do punk, é incontornável o ethos DIY. Este marca, como em todas as cenas punk, as atividades levadas a cabo dentro deste universo e funciona com particular intensidade no acionamento de redes de familiaridade fortes e de interconhecimento mútuo entre os punks portugueses, o que é auxiliado pela pequena dimensão do país. É esse capital relacional informal que proporciona condições de perpetuação do ethos DIY, traduzido no fornecimento e empréstimo de instrumentos, nos meios de transporte, nas logísticas de luz e de som, nas salas ou nos espaços de espetáculo, etc. Aqui, vemos emergir uma comunidade de interesse, de relação, de cumplicidade, que aproxima o punk português da teoria subcultural. Outrossim, também a assunção do punk como modo de vida total, incluindo a estética mas também a ética, aproxima a cena portuguesa das abordagens de Hebdige em 1979.

Em suma, a nossa abordagem demonstra a atualidade do punk enquanto feixe de valores e apropriações diversas, mas confluentes, contraditando as aceções primeiras de Hebdige (1979) em torno de uma lógica subcultural punk, definida num sentido muito estrito (Thornton, 1990). Aliás, o próprio Hebdige admite que hoje a abordagem subcultural teria de ser feita de forma diferente, referindo que essa análise terá de superar as dicotomias "cultura autêntica versus comercial, rua versus mercado, resistência versus incorporação, facto (event) versus representação dos média, etc.” (2012: 409). Este balanço de Hebdige vai ao encontro do nosso objetivo neste artigo: demonstrar a influência do tempo e do espaço na abordagem das culturas juvenis com especial enfoque para a mais "chocante" delas, o punk. E não só o punk, mas o punk em Portugal - contexto absolutamente diferente do "berço" anglo-saxónico (Guerra e Bennett, 2014).

\section{Referências bibliográficas}

Adams, Ruth (2008), "The Englishness of English Punk: Sex Pistols, Subcultures and Nostalgia", Popular Music and Society, 31(4), 469-488.

Albiez, Sean (2003), "Know History!: John Lydon, Cultural Capital and the Prog/Punk Dialectic", Popular Music, 22(3), 357-374.

Albiez, Sean (2004), Punk after Punk: 1978-1984. Consultado a 01.09.2012, em http:// pt.scribd.com/doc/54282068/Punk-After-Punk-1978-1984.

Azerrad, Michael (2002), Our Band Could Be your Life. Boston: Little, Brown and Company.

Barret, Cassandra R.; Burleson, Kathryn (s.d.), Exploring Why Individuals Choose to Belong to Punk Culture: A Qualitative Investigation. North Carolina: Warren Wilson College. 
Bennett, Andy (2001), “Post-war Youth and Rock 'n' Roll”, Cultures of Popular Music. Buckingham, Philadelphia: Open University Press, 7-22.

Bennett, Andy (2006), "Punk's Not Dead: the Continuing Significance of Punk Rock for an Older Generation of Fans", Sociology, 40(2), 219-235.

Bennett, Andy; Peterson, Richard (orgs.) (2004), Music Scenes: Local, Translocal and Virtual. Nashville: Vanderbilt University Press.

Bennett, Andy; Taylor, Jodie (2012), "Popular Music and the Aesthetics of Ageing", Popular Music, 31(2), 231-243.

Bloustien, David (2003), “'Oh Bondage, Up Yours!' Or Here’s Three Chords, Now Form a Band: Punk, Masochism, Skin, Anaclisis, Defacement”, in David Muggleton e Rupert Weinzierl (orgs.), The Post-subcultures Reader. Oxford: Berg, 51-63.

Brake, Mike (1980), The Sociology of Youth Culture and Youth Subcultures: Sex and Drugs and Rock ' $n$ ' Roll. London: Routledge.

Burke, Roger; Sunley, Ros (1998), "Post-Modemism and Youth Subcultures in Britain in the 1990s", in Kayleen M. Hazlehurst e Cameron Hazlehurst (orgs.), Gangs and Youth Subcultures: International Explorations. New Jersey: Transaction Publishing, 35-65.

Cartledge, Frank (1999), "Distress to Impress? Local Punk Fashion and Commodity Exchange", in Roger Sabin (org.), Punk Rock: So What?: The Cultural Legacy of Punk. London: Routledge.

Clark, Dylan (2003), "The Death and Life of Punk, the Last Subculture”, in David Muggleton e Rupert Weinzierl (orgs.), The Post-subcultures Reader. Oxford: Berg, 223-236.

Cogan, Brian (2010), The Encyclopedia of Punk. New York: Sterling Publishing.

Cox, Aleasha (2011), "Youth Gangs in the UK: Myth or Reality?", Internet Journal of Criminology. Consultado a 01.02.2014, em http://www.internetjournalofcriminology. com/Cox_Youth_Gangs_in_the_UK_Myth_or_Reality_IJC_September_2011.pdf.

DeNora, Tia (2000), Music in Everyday Life. Cambridge: Cambridge University Press.

Dunn, Kevin C. (2008), "Never Mind the Bollocks: The Punk Rock Politics of Global Communication", Review of International Studies, 34, 193-210.

Errickson, April (1999), A Detailed Journey into the Punk Subculture: Punk Outreach in Public Libraries. North Carolina: University of North Carolina at Chapel Hill.

Guerra, Paula (2010), A instável leveza do rock: génese, dinâmica e consolidação do rock. alternativo em Portugal (1980-2010). Tese de Doutoramento em Sociologia. Porto: Faculdade de Letras da Universidade do Porto.

Guerra, Paula (2011), "Alta Fidelidade: um roteiro com paragens pelas lojas de discos independentes em Portugal na última década (1998-2010)", Sociologia - Revista da Faculdade de Letras da Universidade do Porto, 21, 23-48.

Guerra, Paula (2014), "Punk, Expectations, Breaches and Metamorphoses: Portugal, 1977-2012”, Critical Arts, 28(1), 111-122.

Guerra, Paula; Bennett, Andy (2014), “Punk Portugal, 1977-2012: A Genealogy”, Poetics [no prelo]. 
Haenfler, Ross (2004), "Rethinking Subcultural Resistance: Core Values of the Straight Edge Movement", Journal of Contemporary Ethnography, 33(4), 406-436.

Hebdige, Dick (1979), Subculture: The Meaning of Style. London: Methuen.

Hebdige, Dick (2012), “Contemporizing 'Subculture': 30 Years to Life”, European Journal of Cultural Studies, 15(3), 399-424.

Hodkinson, Paul (2003), “'Net.Goth': Internet Communication and (Sub)Cultural Boundaries", in David Muggleton e Rupert Weinzierl (orgs.), The Post-subcultures Reader. Oxford: Berg, 285-298.

James, David (1989), "Hardcore: Cultural Resistance in the Postmodern", Film Quarterly, 42(2), 31-39.

James, Kieran (2009), “'This is England': Punk Rock's Realist/Idealist Dialectic and its Implications for Critical Accounting Education”, Accounting Forum, 33(2), 127-145.

Langman, Lauren (2008), "Punk, Porn and Resistance: Carnivalization and the Body in Popular Culture”, Current Sociology, 56(4), 657-677.

Laing, Dave (1978), "Interpreting Punk Rock", Marxism Today, 123-132.

Lentini, Pete (2003), "Punk's Origins: Anglo-American Syncretism”, Journal of Intercultural Studies, 24(2), 153-174.

Marcus, Greil (1989), Lipstick Traces: A Secret History of the Twentieth Century. Cambridge: Harvard University Press.

Mattson, Kevin (2001), "Did Punk Matter? Analysing the Practices of a Youth Subculture during the 1980's", American Studies, 42(1), 69-97.

Matula, Theodore (2007), "Pow! To the People: The Make-Up's Reorganization of Punk Rhetoric", Popular Music and Society, 30(1), 19-38.

Megías, Ignacio Quirós; Rodriguez, Elena San Julián (2001), La identidad juvenil desde las afinidades musicales. Madrid: Instituto de la Juventud.

Moore, Ryan (2004), "Postmodernism and Punk Subculture: Cultures of Authenticity and Deconstruction", The Comunication Review, 7(3), 305-327.

Muglleton, David (2000), Inside Subculture: The Postmodern Meaning of Style. Oxford, New York: Berg.

Muggleton, David; Weinzierl, Rupert (orgs.) (2003), The Post-subcultures Reader. Oxford: Berg.

O'Connor, Alan (2002), "Local Scenes and Dangerous Crossroads: Punk and Theories of Cultural Hybridity”, Popular Music, 21(2), 225-237.

O'Hara, Craig (1999), The Philosopby of Punk. More than Noise. San Francisco/ Edinburgh: AK Press.

Phillipov, Michelle (2006), "Haunted by the Spirit of "77: Punk Studies and the Persistence of Politics”, Continuum, 20(3), 383-393.

Sabin, Roger (1999), Punk Rock: So What?: The Cultural Legacy of Punk. London: Routledge. 
Savage, Jon (2001), England's Dreaming: The Sex Pistols and Punk Rock. London: Faber and Faber.

Simon, Bradford Scott (1997), "Entering the Pit: Slam-dancing and Modernity", The Journal of Popular Culture, 31(1), 149-176.

Sinker, Mark (1999), "Concrete, so as to Self-destruct. The Etiquette of Punk, its Habits, Rules, Values and Dilemmas", Roger Sabin (org.), Punk Rock: So What?: The Cultural Legacy of Punk. London: Routledge.

Thompson, Stacy (2004), Punk Productions: Unfinished State. New York: University of New York Press.

Thornton, Sarah (1990), "Strategies for Reconstructing the Popular Past", Popular Music, 9(1), 87-95.

Tucker, Brian L. (2006), "Punk and the Political: The Role of Practices in Subcultural Lives". Master of Art thesis. Ohio: College of Arts and Sciences of Ohio University. 